\title{
Refractory Carcinoma
}

National Cancer Institute

\section{Source}

National Cancer Institute. Refractory Carcinoma. NCI Thesaurus. Code C8511.

A carcinoma that does not respond to treatment. 